\title{
Proposta para a Gestão de Resíduos Sólidos Urbanos, em Aterro Sanitário, da Cidade de Paraíba do Sul - RJ, Utilizando Indicadores de Custo
}

SOUZA, Alice Magalhães Garcia, VAZQUEZ, Elaine Garrido

Programa de Engenharia Urbana - PEU/POLI/UFRJ

\section{Informações do Artigo}

Histórico:

Recebimento: 26 Outubro 2018

Revisão: 21 Novembro 2018

Aprovação: 21 Dezembro 2018

Palavras-chave:

Resíduos sólidos urbanos

Indicadores de custo

Aterros sanitários

Paraíba do Sul

\section{Resumo:}

O objetivo deste trabalho é propor um modelo adequado de gestão de resíduos sólidos urbanos, baseado na disposição final em aterro sanitário para a cidade de Paraíba do Sul, no estado do Rio de Janeiro, utilizando indicadores de custos. A metodologia utilizada para atingir este objetivo foi a pesquisa exploratória quantitativa baseada em três indicadores: estimativa da geração de resíduos sólidos; estimativa de custos para coleta convencional e estimativa de custos para disposição final dos resíduos sólidos em aterro sanitário. O recorte espacial avaliado contemplou dez bairros do núcleo municipal, escolhidos intencionalmente de acordo com a continuidade do tecido urbano. Os resultados obtidos foram satisfatórios e podem contribuir para a implantação de alguns objetivos da Política Nacional de Resíduos Sólidos no município, notadamente adequar a disposição final de seus resíduos sólidos, que atualmente é feita em um vazadouro a céu aberto. Ao longo do estudo foram observadas também a baixa eficiência de aplicação das leis ambientais sob o contexto de cidades com até 50 mil habitantes e a necessidade de investimentos significativos para adequação da gestão de resíduos sólidos urbanos (RSU) municipal - recursos que podem ser conseguidos através do remanejamento tributário do Imposto Sobre Circulação de Mercadorias e Serviços - conhecido como "ICMS Verde"

\section{Introdução}

A Política Nacional de Resíduos Sólidos (PNRS - lei federal 12.305/2010) instituiu a obrigatoriedade de destinação adequada (aterros sanitários) aos resíduos sólidos de todas as cidades brasileiras no ano de 2010. Apesar disso, dados de 2017 indicam que, dentre os 92 municípios do estado do Rio de Janeiro, 29 ainda destinavam seus resíduos a vazadouros a céu aberto, conhecidos como "lixões". Dentre eles se inclui Paraíba do Sul, cidade objeto deste estudo, ver Figura 1 [1].

Figura 1- Foto do lixão da Barrinha em Paraíba do Sul

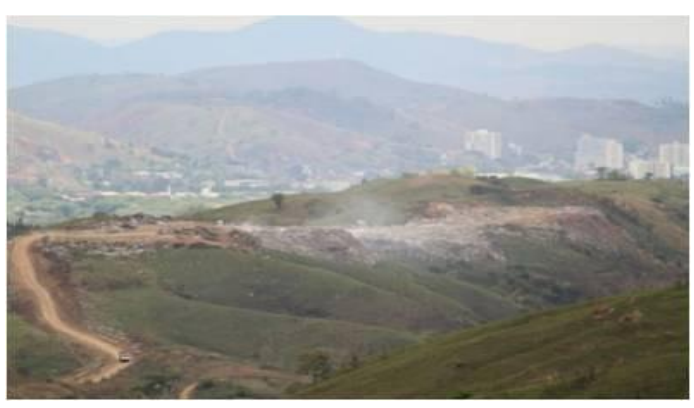

Fonte: Autoras, 2017 
O município integra o Consórcio Serrana 2 para gerenciamento de RSU, junto a outros seis, dentre os quais se inclui o vizinho Três Rios cidade-sede do consórcio onde seria construído um aterro sanitário (AS) com recursos estaduais [2]. Mas, segundo informações veiculadas na imprensa, devido à crise econômica estadual tais recursos não foram liberados. Desta forma, está sendo construído, em Três Rios, um aterro privado com capacidade para $10 \mathrm{mil} \mathrm{t} / \mathrm{mês}$, que espera vencer licitação para recebimento dos resíduos das cidades do consórcio.

Paraíba do Sul fica a $138 \mathrm{~km}$ da capital do estado na divisa com Minas Gerais, região conhecida como Vale do Café (Figura 2). Sua área total é de $587,68 \mathrm{~km}^{2}$ e a população estimada em 2016 era de 42.737 pessoas, o que gera densidade demográfica média de $70 \mathrm{hab} / \mathrm{km}^{2}$.[3]

Figura 2 - Mapa das Mesorregiões do Estado do Rio de Janeiro, indicando a localização da capital e do município de Paraíba do Sul

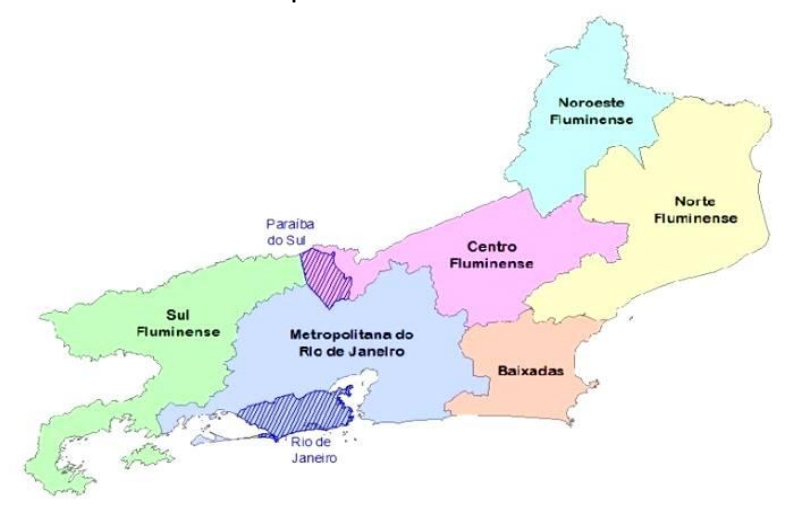

Fonte: Elaboração própria, a partir de IBGE [3]

O município possui extensa área rural, mas é em seu trecho urbanizado (cerca de $10 \mathrm{~km}^{2}$ ) que se concentra cerca de $88 \%$ da população. A cidade surgiu e se desenvolveu ao longo de um trecho do rio de mesmo nome que é o principal manancial de abastecimento da cidade. [4]

A quantidade diária de RSU coletado no município é de $23,5 \mathrm{t} /$ dia [2], dado que se desdobra em 728,5 t/mês e 0,55 kg/hab/dia, ao ser relacionado com a população do município.

Segundo o ex-secretário de meio ambiente de Paraíba do Sul (em entrevista para este trabalho, em março de 2017 - gestão vigente à época), a destinação ambientalmente correta do
RSU sempre foi um problema para os gestores municipais. Ele informou que o RSU coletado no município já foi disposto em um terreno no bairro do Inema, antes de começar a ser enviado aos arredores da Estrada da Barrinha, onde se localiza o vazadouro atual, conforme a Figura 3. Em outro momento, os resíduos de Paraíba do Sul foram enviados ao aterro sanitário do município de Sapucaia, construído por meio de recursos oriundos de um projeto de compensação ambiental da empresa de energia Furnas. Mas há anos a disposição final é feita de forma inadequada no vazadouro citado.

Figura 3 - Mancha urbana de Paraíba do Sul com indicação da localização do vazadouro da Barrinha

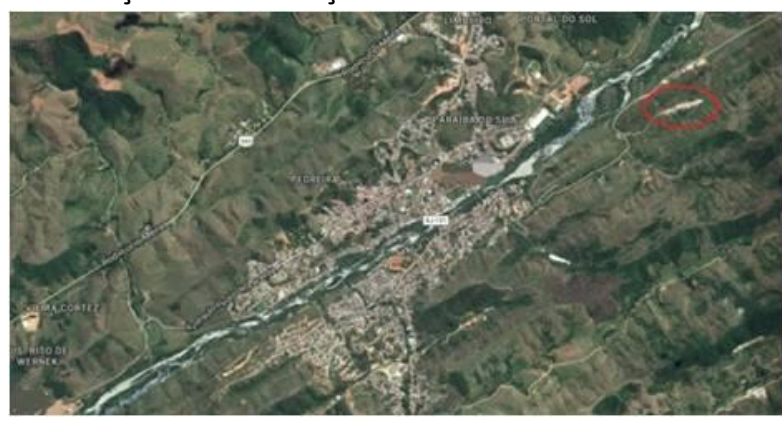

Fonte: Google Maps, 2017, com indicação da autora

A Estrada da Barrinha liga o município ao vizinho Três Rios, sendo uma alternativa à BR-040 para tal percurso. $O$ ex-secretário explicou que quando os resíduos começaram a ser enviados aos arredores da estrada ficavam em locais dispersos, inclusive chegaram a ser dispostos em um terreno próximo à margem do rio Paraíba do Sul. Até que, no ano de 2016 foi contratada uma empresa para recolher, e concentrar todos os resíduos dispersos no local do vazadouro atual (conhecido como "lixão da Barrinha"), que fica em um trecho da estrada um pouco mais distante do rio, no alto de uma encosta.

Em maio de 2018 o Instituto Estadual do Ambiente (INEA) interditou o vazadouro, mas sabe-se que os caminhões continuam levando os resíduos para o local.

$\mathrm{Na}$ entrevista concedida para este trabalho, o secretário de meio ambiente à época informou que a PMPS estudava o possível envio do RSU coletado em Paraíba do Sul ao novo aterro privado de Três Rios - Figura 4. 0 
empreendimento já possui Estudo de Impacto Ambiental (EIA) e Relatório de Impacto Ambiental (RIMA) e as obras foram iniciadas no ano de 2017. Em material de divulgação da União Norte Engenharia, que é a empresa responsável, informa-se que o aterro terá capacidade de recebimento de 10 mil toneladas por mês.

Figura 4 - Foto do aterro sanitário que está sendo implantado no município de Três Rios

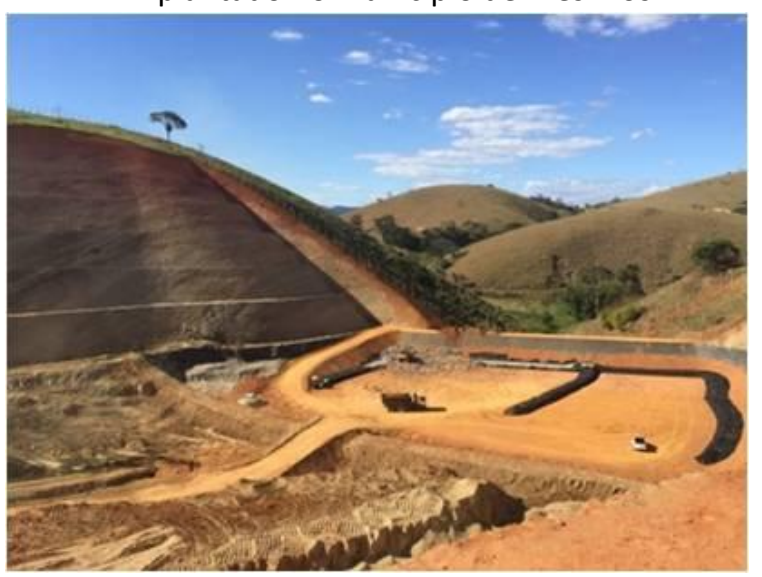

Fonte: site da Prefeitura de Petrópolis <Petrópolis.rj.gov.br>

Paraíba do Sul ainda não concluiu seu Plano Municipal para Gestão Integrada de Resíduos Sólidos (PMGIRS), que está em fase de elaboração, tendo sua versão preliminar divulgada em abril de 2018. Com a conclusão e regulamentação do PMGIRS e o envio do RSU ao novo aterro sanitário de Três Rios, a prefeitura pretende requerer o remanejamento tributário do Imposto Sobre Circulação de Mercadorias e Serviços - conhecido como "ICMS Verde". Seu valor foi simulado em $\mathrm{R} \$ 449.522,91$ anuais [2]. Tal recurso auxiliaria no financiamento da própria gestão de RSU e em melhorias para o sistema.

\subsection{Objetivos}

O objetivo deste artigo é apresentar uma proposta para a gestão de RSU no município de Paraíba do Sul, sob indicadores de custos de coleta e disposição final. O cenário avaliado foi denominado Cenário Simulado (CS) e terá como premissas: a coleta convencional em um recorte espacial pré-definido e o envio do RSU coletado neste recorte ao novo aterro sanitário privado de Três Rios (ASTR).

\subsection{Aterros Sanitários}

Conforme documento produzido pelo Instituto Brasileiro de Administração Municipal [5]: “O aterro sanitário é uma obra de engenharia projetada sob critérios técnicos, cuja finalidade é garantir a disposição dos resíduos sólidos urbanos sem causar danos à saúde pública e ao meio ambiente".

"É considerado uma das técnicas mais eficientes e seguras de destinação de resíduos sólidos (...)" [5]

É importante ressaltar que um Aterro Sanitário (AS) nada tem a ver com um vazadouro a céu aberto. $O$ vazadouro é simplesmente um local onde se começou a depositar resíduos, sem qualquer tipo de controle ambiental. Já o AS é um espaço projetado para o recebimento de resíduos, dispondo de camada de impermeabilização do fundo, cobrimento do maciço, recolhimento de gases e lixiviado, controle do fluxo de caminhões de coleta, células separadas por tipo de resíduos etc. [6]

Uma situação intermediária entre um e outro é o chamado Aterro Controlado, que seria algo como um "vazadouro remediado", um "lixão" que passou por procedimentos mínimos de controle. [6]

Apesar de o AS não ser a única solução para a Gestão de RSU, qualquer forma de tratamento de RSU precisa, em última instância, de uma solução para disposição final dos rejeitos gerados no processo e o AS é, atualmente, a mais adequada ambientalmente.

Conforme a Pesquisa Nacional de Saneamento Básico de 2008 [7], o aterramento (em AS ou lixões) é a forma mais utilizada de disposição final de resíduos no Brasil.

Os custos de um AS podem variar muito conforme seu tamanho, capacidade de operação, previsão de vida útil, tipo de gestão (pública ou privada) e conforme sua escala de geração de RS (larga ou pequena escala de geração). 
Segundo Barros [6] os custos de um sistema de disposição final de RS variam entre 10 e $20 \%$ dos custos das atividades de limpeza, em geral. 0 autor afirma que, no Brasil, a resistência pela cobrança de tais custos à população é um grande empecilho a possíveis melhorias na Gestão de RSU.

O estudo de Rodrigues [8] indica que a disposição de RSU em aterros de gestão privada costuma sair mais caro para a municipalidade, quando comparada à disposição em aterros públicos. Entretanto, o autor pondera que a gestão pública dos aterros nem sempre é eficiente, devido, sobretudo, à ausência de um agente regulador independente. $O$ estudo indica ainda que municípios menores (até 500 mil habitantes) pagam mais caro pelos serviços de RSU, em comparação com cidades maiores (mais de 5 milhões de habitantes).

Dentre as vantagens da disposição final em um AS pode-se citar: a capacidade de absorver RS de diferentes tipos em grandes quantidades; a eliminação da presença de catadores; o controle da proliferação de vetores (por conta do cobrimento diário); a drenagem dos lixiviados (evitando que se infiltrem e contaminem o lençol freático); a possibilidade de aproveitamento do biogás para geração de energia; e ainda, após o seu fechamento, a possibilidade de recuperação de áreas degradadas e desvalorizadas economicamente para fins de lazer público. Tais vantagens têm como benefício maior a preservação do meio ambiente e a melhora da qualidade de vida no meio urbano.

Em contrapartida, os inconvenientes do AS seriam: a demanda por uma extensa área para sua implantação (nem tão perto nem tão longe dos centros geradores para que não inviabilize a logística - o que é difícil conseguir em áreas intensamente urbanizadas); sua vulnerabilidade às condições pluviométricas locais; a necessidade de grandes quantidades de material para recobrimento (de preferência disponível em áreas adjacentes); a produção de ruídos, decorrentes de sua operação (muitas vezes também durante a noite) e a desvalorização de áreas em seu entorno, dentre outros.
Além de tais desvantagens, existem também riscos de operação do AS, tais como: explosões geradas pela geração/acumulação de biogás e o contato do metano com o oxigênio; acidentes causados por recalques diferenciais não previstos no projeto do AS; contaminação do solo e das águas superficiais e subterrâneas, por conta de vazamentos do lixiviado; poluição atmosférica, pelo escapamento dos gases; e o transporte dos resíduos pelo vento, causado por falta ou inadequação do recobrimento. Esses riscos ocorrem por falhas na operação, ou pela falta de controle e monitoramento adequados dos processos e rotinas do AS - que podem ser ocasionados por falta de verbas suficientes, mágestão, dentre outros problemas.

\section{Método}

Este trabalho apresenta resultados de uma pesquisa exploratória quantitativa, avaliando aspectos de custos dos dados levantados.

A amostra utilizada na pesquisa foi composta de dez bairros da sede municipal, escolhidos intencionalmente, de forma não aleatória, conforme um recorte espacial que levou em consideração a continuidade do tecido urbano. Ou seja, a amostra é não probabilística, [9] mas representativa do universo de estudo, pois na sede municipal estão presentes a maior parte dos habitantes e, por conseguinte, é onde se gera a maior parcela do RSU.

Parte do levantamento de dados foi realizada por meio de entrevista não estruturada do tipo "focalizada". Ou seja, houve um roteiro prévio de perguntas que foi alterado durante a conversação, de modo a enfocar os aspectos mais relevantes do tema pesquisado. [9]

A seguir serão apresentados os instrumentos, as fontes e os parâmetros do método de pesquisa para cada um dos indicadores propostos na avaliação dos cenários simulados neste artigo.

\subsection{Estimativas de geração de RSU, em t/mês}

Para definir este indicador, primeiro foi definido um recorte espacial e realizado o 
levantamento da área e da população deste recorte de bairros.

O recorte espacial contempla dez bairros que compõem o tecido urbano contínuo do município, deixando de fora alguns outros bairros e os núcleos-sede afastados da área mais densa. Para definição da área e da população deste recorte foram utilizados dados do Plano Diretor de Desenvolvimento Territorial (PDDT) de Paraíba do Sul [10], apresentados na Tabela 1 (ANEXO A), em conjunto com a informação - também presente no documento - de que $88 \%$ da população de Paraíba do Sul se concentra nas áreas urbanas adensadas.

A quantidade total de RSU recolhida neste universo foi estimada, em toneladas por dia, a partir do dado de $0,55 \mathrm{~kg} / \mathrm{hab} / \mathrm{dia}$, descrito na Introdução e posteriormente convertida para t/mês.

\subsection{Estimativas de Custo de Coleta, em RȘ/Mês}

Este indicador é composto de dois itens: consumo médio de combustível dos veículos e salários dos funcionários da coleta. Para essas estimativas foram utilizadas as seguintes orientações presentes em [11]: “(...) sabemos que praticamente não existe um processo de apropriação de custos dos serviços de manejo de resíduos sólidos na maioria dos municípios. Entretanto, esforço neste sentido deverá ser feito a partir de custos unitários, buscando verificar a carga horária de funcionários, equipamentos utilizados, ou dos valores de contratos, quando houver." [11]

O documento orienta, ainda, a produção de mapas com as rotas da coleta, alertando para a dificuldade de encontrar tais documentos em municípios menores - como foi o caso deste estudo: “(...) poderão ser utilizados mapas em papel e as informações devem ser armazenadas em programas indicados pela escolha do sistema de georreferenciamento. É provável que os municípios menores não disponham de mapa próprio da Prefeitura; mas é possível obter mapas de fontes oficiais para os diversos municípios, (como o IBGE, por exemplo). Nestes mapas devese identificar em cada município do consórcio quem são e onde estão os geradores orgânicos não domiciliares (...)" [11]

Neste artigo foram utilizados os sistemas digitais Google Maps e Google Earth , e suas funcionalidades (rotas e marcadores) para identificação dos mapas e locais relevantes e para a definição da extensão dos trajetos estudados.

Não foram contemplados os custos com: aquisição, depreciação, manutenção, taxas de seguro e licenciamento dos veículos coletores, bem como encargos e benefícios dos funcionários, despesas com uniformes e EPIs para o serviço de coleta e impostos.

\subsubsection{Consumo Médio de Combustível dos Veículos}

Para a definição deste item foram estipulados o tipo de veículo a ser utilizado e as distâncias a percorrer.

Simulou-se o uso do caminhão compactador com capacidade para $19 \mathrm{~m}^{3}$ - correspondente a $5,7 \mathrm{t}$ de resíduos [12]. Tal modelo de caminhão é, de fato, utilizado atualmente na cidade para a coleta de resíduos sólidos.

Foram estabelecidos dois tipos de distâncias (km/ mês) para o CS: distância D1, referente à logística dos resíduos já coletados até o seu destino final e distância D2 - referente à coleta casa por casa.

Assim, D1 é a distância entre o centro urbano de Paraíba do Sul e o ASTR e D2 foi definida através do método descrito a seguir: mapeou-se três regiões distintas do recorte de bairros proposto e mediu-se a quilometragem de suas ruas através do software AutoCAD, conforme a Figura 5 (ANEXO B).

Cada região mapeada possui área de 250.000 $\mathrm{m}^{2}$, ou $0,25 \mathrm{~km}^{2}$ (conforme quadrados com $500 \mathrm{~m}$ de lado) e foram escolhidas regiões que possuíssem padrões de ocupação e arruamento diferenciados entre si - de forma que se chegasse a uma média representativa do recorte espacial estudado.

A Região 1 - Palhas - possui $4 \mathrm{~km}$ de ruas; a Região 2 - Jatobá - possui $1,7 \mathrm{~km}$ de ruas e a Região 3 - Centro - possui $3 \mathrm{~km}$ de ruas. 
Portanto, a média entre as quilometragens das três regiões foi de $2,9 \mathrm{~km}$.

Desta forma chegou-se à estimativa de que $0,25 \mathrm{~km}^{2}$ equivale à média $2,9 \mathrm{~km}$ lineares de ruas a serem percorridas. Então, por meio de regra de 3 , tem-se que $1 \mathrm{~km}^{2}$ equivale a $11,6 \mathrm{~km}$ lineares de ruas a serem percorridas. A partir destas três regiões mapeadas minuciosamente, estimou-se as demais regiões pela área total de cada bairro, em $\mathrm{km}^{2}$ (conforme a coluna "Área Total", da tabela 1 - ANEXO A). Assim, tem-se:

- Palhas $\left(2,02 \mathrm{~km}^{2}\right)$ - total estimado de $23 \mathrm{~km}$ de ruas

- Brocotó $\left(0,49 \mathrm{~km}^{2}\right)$ - total estimado de $6 \mathrm{~km}$ de ruas

- Centro $\left(0,63 \mathrm{~km}^{2}\right)$ - total estimado de $7 \mathrm{~km}$ de ruas

- Lavapés $\left(0,45 \mathrm{~km}^{2}\right)$ - total estimado de $5 \mathrm{~km}$ de ruas

- Parque Morone $\left(1,50 \mathrm{~km}^{2}\right)$ - total estimado de $17 \mathrm{~km}$ de ruas

- Cerâmica D'Ângelo $\left(0,87 \mathrm{~km}^{2}\right)$ - total estimado de $10 \mathrm{~km}$ de ruas

- Grama $\left(1,23 \mathrm{~km}^{2}\right)$ - total estimado de $14 \mathrm{~km}$ de ruas

- Jatobá $\left(1,32 \mathrm{~km}^{2}\right)$ - total estimado de $15 \mathrm{~km}$ de ruas

- Niágara $\left(0,21 \mathrm{~km}^{2}\right)$ - total estimado de $2 \mathrm{~km}$ de ruas

- Bela Vista $\left(1,28 \mathrm{~km}^{2}\right)$ - total estimado de 14 $\mathrm{km}$ de ruas.

O total estimado para todos os bairros do recorte ficou em $113 \mathrm{~km}$ de ruas a serem percorridos pelos caminhões de coleta referente à distância D2.

Por fim, para calcular o consumo médio de combustível utilizou-se a estimativa de Lino [13]: $0,433 \mathrm{~L} / \mathrm{km}$. Para determinar esta média, a autora comparou diversos estudos de consumo de combustível em caminhões de carga comum e de resíduos sólidos. Tais estudos levaram em conta variáveis como: tipo de caminhão, tempo de acionamento do dispositivo mecânico de coleta, distância percorrida, número de paradas, situação do tráfego, limite de velocidade e habilidade da equipe.
O combustível utilizado em caminhões é o óleo diesel que na região de Paraíba do Sul, custa atualmente cerca de $\mathrm{R} \$ 3,254 / \mathrm{L}$. Este valor foi definido a partir da média entre os valores pesquisados nas cidades do Rio de Janeiro, Sapucaia e Teresópolis, que se encontravam disponíveis no site da Agência Nacional do Petróleo [14].

\subsubsection{Salários dos Funcionários da Coleta}

Os salários dos coletores e motoristas foram estimados através de Borges \& Ferreira [15]: R\$ 478,73 e $\mathrm{R} \$$ 500,00, respectivamente e corrigidos conforme o Índice Nacional de Preço ao Consumidor (INPC). Utilizouse o salário mínimo corrente no ano de 2017 ( $R \$$ 937,00) para valores corrigidos abaixo deste.

No CS proposto simulou-se a coleta convencional uma vez ao dia, exceto domingos (média de 28 dias/mês), realizada por quatro funcionários (um motorista e três coletores) em cada caminhão.

\subsubsection{Estimativas de Custos para Disposição Final de Resíduos, em R\$̣/mês}

Para determinar os custos da disposição final no ASTR, foi corrigido o valor de $R \$ 54,25 / t$, descrito no Plano Nacional de Resíduos Sólidos [16], conforme o Índice de Preços ao Consumidor Amplo (IPCA), em novembro de 2017.

\section{Resultados}

O cenário proposto contempla o envio de todo o RSU coletado no recorte proposto ao ASTR. A Figura 6 a seguir apresenta o fluxograma para este cenário.

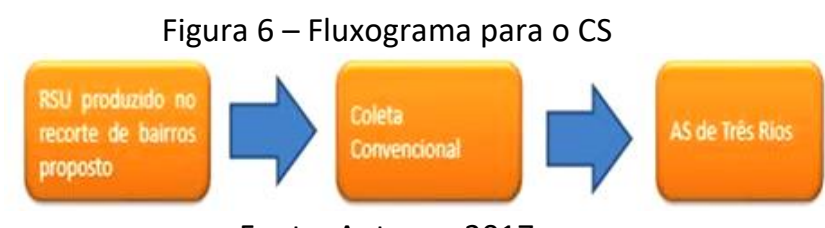

Fonte: Autoras, 2017

A seguir será apresentado o levantamento de dados e a aplicação para cada indicador deste trabalho. 


\subsection{Estimativa de Geração de RSU}

Os dez bairros contemplados no recorte espacial proposto compõem o tecido urbano contínuo do município. São eles: Bela Vista, Brocotó, Centro, Cerâmica D'Ângelo, Grama, Jatobá, Lavapés, Niágara, Palhas e Parque Morone - Figura 7. Os bairros LimoeiroLiberdade, Santo Antônio e Fernandó, apesar de estarem na mesma mancha urbana do mapa, possuem características morfológicas ou limites que os fazem se destacar dos demais, como a presença de uma rodovia ou o relevo acentuado.

Conforme descrito no PDDT [10], 88\% da população municipal de Paraíba do Sul concentra-se nas áreas urbanas adensadas. Sendo a população total $(100 \%)$ do município de 42.737 habitantes, a porcentagem de $88 \%$ resulta em 37.608 habitantes.

Figura 7 - Mapa das areas urbanas de Paraíba do sul, indicando os bairros de maior adensamento

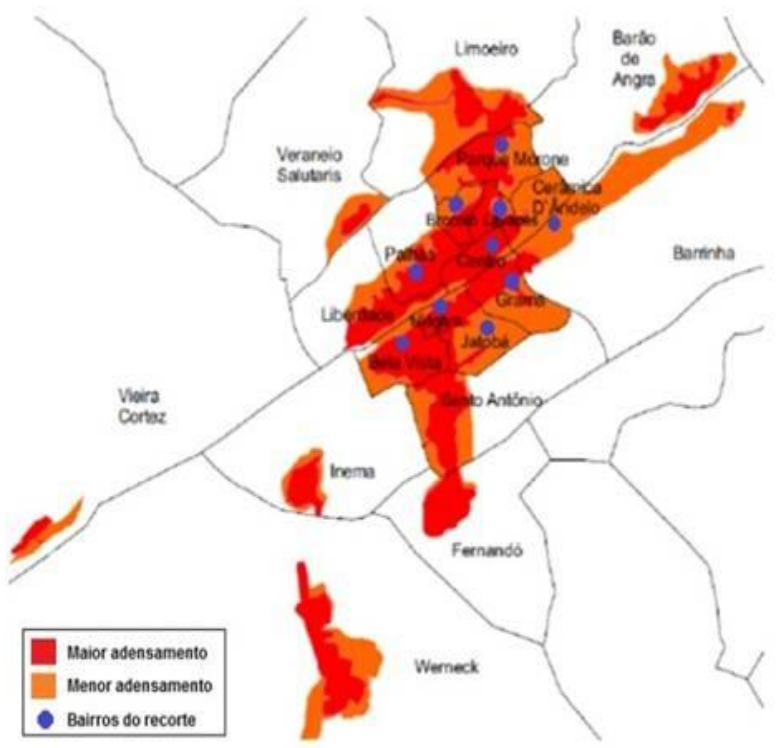

Fonte: Plano Diretor de Desenvolvimento

Territorial de Paraíba do Sul, adaptado

Para os bairros do recorte, o somatório das áreas ocupadas é $4,61 \mathrm{~km}^{2}$, ver Tabela 1 . A partir deste dado e do dado anterior (37.608 pessoas vivem em $9.68 \mathrm{~km}^{2}$ ), utilizou-se regra de três para definir a população dos bairros do recorte, obtendo-se a população de 17.910 habitantes nos bairros do recorte. A Tabela 2 a seguir mostra um resumo dos dados de área e população levantados.

Tabela 2 - Resumo dos dados de area e população do recorte especial proposto

\begin{tabular}{|c|c|}
\hline Descrição & Dado \\
\hline População total do município & 42.737 habitantes \\
\hline População que habita a área urbana ( $88 \%$ do total) & 37.608 habitantes \\
\hline $\begin{array}{l}\text { Somatório de todas as áreas ocupadas do município, segundo a } \\
\text { tabela } 1\end{array}$ & $9,68 \mathrm{~km}^{2}$ \\
\hline $\begin{array}{l}\text { Somatório das áreas ocupadas dos } 10 \text { bairros do recorte (Palhas, } \\
\text { Brocotó, Centro, Lavapés, Parque Morone, Cerâmica } \\
\text { D’Ângelo, Grama, Jatobá, Niágara e Bela Vista) }\end{array}$ & $4,61 \mathrm{~km}^{2}$ \\
\hline População que habita a área do recorte $\left(4,61 \mathrm{~km}^{2}\right)$ & 17.910 habitantes \\
\hline
\end{tabular}

Fonte: Autoras, 2017

Assim, a área estudada neste artigo possui $4,61 \mathrm{~km}^{2}$, e sua respectiva população é de 17.910 habitantes.

A partir do dado de $0,55 \mathrm{~kg} / \mathrm{hab} / \mathrm{dia}$, e da população total do recorte espacial proposto (17.910 hab.), tem-se uma produção de 9,85 t/dia de RSU nos bairros analisados, que se converte em 305,4 t/mês.

\subsection{Estimativas de Custo de Coleta}

\subsubsection{Consumo Médio de Combustível dos Veículos}

Para determinar o consumo médio de combustível, primeiro foi definida a quantidade de veículos necessária. Conforme dados da empresa de coleta municipal, a mesma dispõe de dois caminhões compactadores para atendimento da sede urbana. Cruzando tal informação com a estimativa de geração de RSU total no recorte $(9,85 \mathrm{t} / \mathrm{dia})$, tem-se a necessidade de dois caminhões com capacidade para $19 \mathrm{~m}^{3}$ $(5,7 \mathrm{t})$ para a coleta nos bairros escolhidos.

A partir disso, prosseguiu-se às estimativas das distâncias D1 e D2. Para D1, buscou-se a localização do ASTR (Relatório de Impacto Ambiental do empreendimento, 2015) [15] e da empresa de limpeza pública (que fica na sede urbana de Paraíba do Sul, dentro da área do recorte proposto). Por meio da funcionalidade rotas da ferramenta Google Maps, gerou-se o dado de $17,8 \mathrm{~km}$ por viagem. Esta quilometragem foi multiplicada por quatro, considerando ida e 
volta da garagem da empresa de limpeza pelos dois caminhões.

Assim, tem-se $71,2 \mathrm{~km} /$ dia no total. Ao multiplicar este valor pela média de 28 dias de coleta, tem-se que D1 $=1.994 \mathrm{~km} / \mathrm{mês}$.

Para D2 multiplicou-se a média de 113 $\mathrm{km} /$ dia por 28 dias. Então, tem-se que D2 = 3.164 $\mathrm{km} / \mathrm{mês}$. Cada caminhão percorrerá metade dessa distância.

Ao somar D1 e D2, estimou-se a distância total a ser percorrida em $5.158 \mathrm{~km} / \mathrm{mês}$.

Para definir o custo do combustível, definiuse o consumo médio de $2.233 \mathrm{~L} / \mathrm{mês}$ de óleo diesel para a coleta convencional (a partir do índice 0,433 L/km - [13] ), que será dividido entre os 2 caminhões compactadores. Multiplicando-se este dado pelo valor do diesel por litro (R\$ $3,254 / \mathrm{L})$, tem-se o custo mensal médio estimado para o consumo de combustível da coleta convencional de $\mathrm{R} \$ 7.266,18$, que pode ser arredondado para $\mathrm{R} \$ 7.500,00 /$ mês.

\subsubsection{Salários dos Funcionários da Coleta}

No cenário simulado tem-se três coletores e um motorista por caminhão, totalizando seis coletores e dois motoristas. Corrigindo-se os valores de Borges \& Ferreira [16] segundo o INPC, tem-se: $\mathrm{R} \$$ 914,60 para coletores, e $\mathrm{R} \$ 955,23$ para motoristas. Como o salário dos coletores corrigido ficou abaixo do salário mínimo corrente no ano de 2017, foi utilizado o valor do último: $\mathrm{R} \$$ 937,00 . Desta forma, o custo total com os salários dos oito funcionários foi de $\mathrm{R} \$ 7.532,46 / \mathrm{mês}$.

Por fim, calculou-se o custo mensal com a coleta convencional somando os custos do consumo de combustível $(R \$ 7.500,00)$ com os salários dos funcionários ( $R \$ 7.532,46$ ), chegando ao valor total de $\mathrm{R} \$ 15.032,46 / \mathrm{mês}$, que pode ser arredondado para $\mathrm{R} \$ 15.500,00 / \mathrm{mês}$.

\subsubsection{Estimativas de Custos para Disposição} Final de Residues

O custo por tonelada para recebimento dos resíduos no AS de Três Rios não foi divulgado pela empresa União Norte Engenharia, responsável pela construção do aterro. A PMPS também não possuía tal dado à época da coleta de dados para este artigo.

Assim, foi utilizado o valor de $\mathrm{R} \$ 54,25 / \mathrm{t}$, referente ao ano de 2008 (Plano Nac. de Resíduos Sólidos - BRASIL [17] ). Este valor foi corrigido conforme a inflação do período (2008 - 2017), pelo IPCA, obtendo-se o valor de $\mathrm{R} \$ 92,15 / \mathrm{t}$. Tal resultado está dentro dos padrões comumente aceitos na área de RSU (entre R\$ 80,00/t e R\$ $110,00 / t$ ) - padrões estes que não estão disponíveis na literatura.

Ao multiplicar este valor pela quantidade total de RSU (305,4t/mês), obtém-se R\$ 28.142,61 / mês para a disposição final de resíduos no aterro, no CS - valor arredondado para $\mathrm{R} \$ 28.500,00$ / mês.

\subsection{Resumo do Cenário Simulado}

Conforme os dados levantados e os resultados obtidos, pode-se estabelecer o resumo a seguir, para o CS:

- O total de RSU recolhido a ser enviado ao AS de Três Rios é de 305,4t/mês;

- A coleta convencional, acrescida do trajeto dos caminhões até o AS, custaria aproximadamente $\mathrm{R} \$ \mathbf{1} 15.500,00 /$ mês à PMPS;

- O aterro, por ser privado, cobra R\$92,15/t para a disposição final, sendo o valor total para a disposição final de todo o RSU coletado no recorte proposto de aproximadamente $\mathrm{R} \$ 28.500,00 /$ mês.

A partir dos indicadores acima, tem-se que o custo mensal da PMPS para coleta e disposição final dos resíduos gerados no recorte proposto é de aproximadamente $R \$ 44.000,00$. A Tabela 3 a seguir mostra os valores finais para o cenário simulado.

Tabela 3 - Valores absolutes dos indicadores de custos para o cenário proposto

\begin{tabular}{r|c}
\hline \multicolumn{1}{c|}{ Indicadores de Custo } & Valores (RS) \\
\hline Coleta (s) & $15.500,00$ \\
\hline $\begin{array}{l}\text { Disposição Final no Aterro - RS } \\
\text { heterogêneos }\end{array}$ & $28.500,00$ \\
\hline TOTAIS & $44.000,00$ \\
\hline
\end{tabular}

Fonte: Autoras, 2017 


\section{Considerações Finais}

O gerenciamento de resíduos no Brasil ainda apresenta deficiências no que se refere à disposição final adequada e erradicação dos vazadouros a céu aberto.

Buscou-se, neste artigo, avaliar o custo para a disposição dos resíduos sólidos urbanos em um aterro sanitário privado, em um contexto municipal abaixo de 50 mil habitantes, sob um cenário simulado de gestão em um recorte espacial intencional. $\mathrm{O}$ objetivo foi alcançado satisfatoriamente através dos indicadores propostos.

A situação da gestão de resíduos no município objeto deste estudo traz à tona a falta de eficiência na aplicação das leis ambientais, sobretudo em contextos de cidades menores. Paraíba do Sul ainda não concluiu seu Plano Municipal para Gestão Integrada de Resíduos Sólidos (PMGIRS) e utiliza um vazadouro a céu aberto para disposição de seus resíduos sólidos, o que causa impactos negativos no meio ambiente, sobretudo tratando-se de uma cidade que cresce à beira de um importante rio para o Estado do Rio de Janeiro.

É importante relembrar que aterros privados costumam cobrar mais caro pela disposição final, do que os geridos pelo poder público. Contudo, a prefeitura de Paraíba do Sul certamente não dispõe de recursos suficientes para implantar e gerir um AS próprio.

O custo mensal de gerenciamento do RSU obtido para o cenário simulado neste artigo ( $R$ \$ $44.000,00$ ) parece alto para um município de pequeno porte que não possui fontes relevantes de recursos. Porém, com a conclusão do PMGIRS e o envio dos resíduos ao ASTR, pode ser requerido o remanejamento do ICMS no valor de R\$ R\$ 449.522,91 anuais (SEA, 2013) - recurso que pode auxiliar no financiamento desta despesa.

É importante ressaltar que esta simulação desconsidera custos significativos, relativos à depreciação de equipamentos, impostos, taxas e seguros de veículos, encargos e benefícios de funcionários. Acredita-se que um estudo de viabilidade estabeleceria um valor final cerca de
30 a $40 \%$ mais alto do que este. Além disso, o cenário simulado contemplou apenas 10 bairros do município, com a respectiva geração de 305,4 t/mês de RSU (de um total estimado em 728,5 t/ mês). Assim, estima-se que os recursos referentes ao ICMS Verde financiariam apenas um quarto do custo anual de gestão de RSU do município.

Convém à PMPS estudar a viabilidade econômica de tal arranjo, já que está se direcionando neste sentido. Além disso, seria interessante avaliar a possibilidade de alternativas de recuperação e valorização de resíduos, como a reciclagem e a compostagem, de forma a reduzir as quantidades a serem aterradas.

Apesar disso, destaca-se no contexto brasileiro, o fato de muitos tipos de resíduos ainda precisarem de aterramento, por não haver mercado de reciclagem consolidado para determinados tipos de materiais, ou alternativas de tratamento adequadas a eles. Além disso, em um cenário no qual grande parte dos municípios ainda utilizam "lixões" para dispor seus resíduos, pode-se vislumbrar um longo caminho até a implantação de alternativas menos impactantes ao meio-ambiente (integradas aos AS que seriam exclusivos para rejeitos).

\section{Referências}

[1] Instituto Trata Brasil: $<w w w . t r a t a b r a s i l . o r g . b r>$ Acesso em junho de 2017.

[2] Secretaria de Estado do Ambiente. Governo do Estado do Rio de Janeiro. Consultoria e Assessoria Técnica de Engenharia à SEA para Elaboração do Plano Estadual de Resíduos Sólidos - Vol.3. SEA e Ecologus Engenharia Consultiva, 2013.

[3] IBGE Cidades: <cidades.ibge.gov.br> Acesso em junho de 2017.

[4] Comitê de Integração da Bacia Hidrográfica do Rio Paraíba do Sul. Observatório SIGA-CEIVAP: <sigaceivap.org.br/ 
observatorioMunicipio> Acesso em junho de 2017.

[5] ELK, A.G.H.P. Mecanismo de desenvolvimento limpo aplicado a resíduos sólidos: Redução de emissões na disposição final. Rio de Janeiro: IBAM, 2007.

[6] BARROS, R.T.V. Elementos de Gestão de Resíduos Sólidos. Belo Horizonte: Tessitura, 2012.

[7] INSTITUTO BRASILEIRO DE GEOGRAFIA E ESTATÍSTICA. Pesquisa Nacional de Saneamento Básico - 2008. Rio de Janeiro, 2010.

[8] RODRIGUES, W; MAGALHÃES FILHO, L.N.L.; PEREIRA, R.S. Análise dos Determinantes dos custos de resíduos sólidos urbanos nas capitais estaduais brasileiras. Urbe. Revista Brasileira de Gestão Urbana, 2016..

[9] BARROS, A.J.P.; LEHFELD, N.A.S. Fundamentos de Metodologia: Um guia para a iniciação científica. São Paulo: McGraw-Hill, 1986.

[10] PREFEITURA MUNICIPAL DE PARAÍBA DO SUL. Plano Diretor de Ordenamento Territorial de Paraíba do Sul, RJ.

[11] MINISTÉRIO DO MEIO AMBIENTE. Manual para Implantação de Compostagem e de Coleta Seletiva no Âmbito de Consórcios Públicos. Projeto Internacional de Cooperação Técnica para a Melhoria da Gestão Ambiental no Brasil BRA/OEA/08/001. Secretaria de Recursos Hídricos e Ambiente Urbano. Brasília, 2010.

[12] PROSAB 3. Resíduos Sólidos Urbanos: aterro sustentável para municípios de pequeno porte. Armando Castilho Jr. (coord.). Florianópolis, SC, 2003.

[13] LINO, F.A.M. Consumo de energia no transporte da coleta seletiva de resíduo sólido domiciliar no município de Campinas (SP). Dissertação - Engenharia Mecânica UNIVERSIDADE ESTADUAL DE CAMPINAS. 2009

[14] Agencia Nacional do Petróleo. <anp.gov.br> Acesso em novembro de 2017.
[15] Relatório de Impacto Ambiental Central de Tratamento de Resíduos Sólidos de Três Rios. União Norte Engenharia; Ecologic Inteligência Ambiental, 2015. Disponível em "Rede Ambiente Participativo" - Ministério Público: <https://www.google. com/url?hl=ptBR\&q=http://rj.rap.gov.br/central-detratamento-e-destinacao-de-residuos-solidos-detres-rios $/$ \&source $=$ gmail\&ust $=150981215$ 0336000\&usg=AFQjCNGS6thia_1P_7HcFJrDMM9j4_y8Q> Acesso em outubro de 2017

[16] BORGES, M.R.P.; FERREIRA, O.M. Limpeza Urbana - Análise dos custos dos serviços realizados em Aparecida de Goiânia. Universidade Católica de Goiás - Engenharia Ambiental. Goiânia, 2008. [17] BRASIL, Ministério do Meio Ambiente. Plano Nacional de Resíduos Sólidos. Brasília, 2012. Disponível em <http://www.sinir. gov.br/web/guest/planonacional-de-residuos-solidos $>$ Acesso em setembro de 2017.

*Alice M. G. Souza é mestre em Engenharia Urbana pelo Programa de Engenharia Urbana (PEU/POLI-UFRJ) 


\section{ANEXO A}

Tabela 1 - Relação de áreas totais e ocupadas dos bairros e núcleos-sede do município de Paraíba do Sul, destacando os bairros do recorte espacial proposto neste trabalho

\begin{tabular}{|c|c|c|c|c|c|}
\hline BAIRRO & $\begin{array}{c}\text { A TOTAL } \\
\left(\mathrm{km}^{2}\right)\end{array}$ & $\begin{array}{c}\text { A OCUPADA } \\
\left(\mathrm{km}^{2}\right)\end{array}$ & BAIRRO & $\begin{array}{l}\text { A TOTAL } \\
\left(\mathbf{k m}^{2}\right)\end{array}$ & $\begin{array}{c}\text { A OCUPADA } \\
\left(\mathrm{km}^{2}\right)\end{array}$ \\
\hline Barão de Angra & 8,57 & 0,51 & Lavapés & 0,45 & 0,36 \\
\hline Barrinha & 14,75 & 0,14 & Liberdade & 2,77 & 0,57 \\
\hline Brocotó & 0,49 & 0,23 & Limoeiro & 93,71 & 0,72 \\
\hline Bela Vista & 1,28 & 0,85 & Niágara & 0,21 & 0,16 \\
\hline Centro & 0,63 & 0,57 & Palhas & 2,02 & 0,69 \\
\hline Cerâmica D'Ângelo & 0,87 & 0,11 & Pque. Morone & 1,5 & 0,7 \\
\hline Fernandó & 6,16 & 0,61 & Sto. Antônio & 4,25 & 0,81 \\
\hline Grama & 1,23 & 0,46 & Veraneio Salutaris & 9,94 & 0,14 \\
\hline Inema & 6,61 & 0,37 & Vieira Cortez & 90,17 & 0,13 \\
\hline \multirow[t]{2}{*}{ Jatobá } & 1,32 & 0,48 & Werneck & 67,86 & 1,07 \\
\hline & & & TOTAIS & 314,79 & 9,68 \\
\hline
\end{tabular}

Fonte: Elaboração própria, utilizando dados do PDDT [10], 2017 
ANEXO B

Figura 5 - Mapa das três regiões escolhidas no recorte de bairros proposto para definição de quilometragem das rotas de coletas

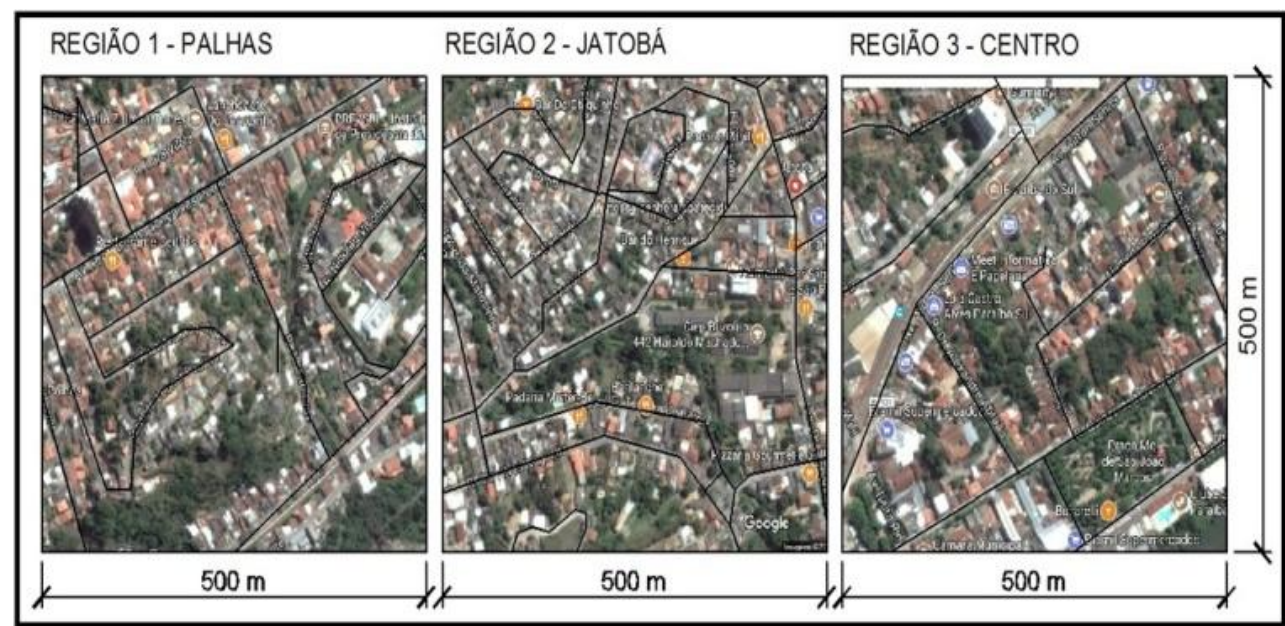

Fonte: elaboração própria, a partir de Google Maps e AutoCAD, 2017 